\title{
The Use of Part-of-Speech Tagging on E-Newspaper in Improving Grammar Teaching Pedagogy
}

\author{
Ruzana Omar ${ }^{1}$, Sarah Yusoff ${ }^{2}$, Radzuwan Ab Rashid ${ }^{3}$, Azweed Mohamad ${ }^{3} \&$ Kamariah Yunus ${ }^{3}$ \\ ${ }^{1}$ Academy of Language Studies, University Technology MARA, Malaysia \\ ${ }^{2}$ Faculty of Computer and Mathematical Sciences, University Technology MARA, Malaysia \\ ${ }^{3}$ Faculty of Languages and Communication, Universiti Sultan Zainal Abidin, Malaysia \\ Correspondence: Ruzana Omar, Academy of Language Studies, University Technology MARA, Malaysia. \\ E-mail: ruzana@tganu.uitm.edu.my
}

Received: May 23, 2018 Accepted: June 20, 2018 Online Published: November 27, 2018

doi:10.5539/ijel.v8n7p1 URL: https://doi.org/10.5539/ijel.v8n7p1

\begin{abstract}
One of the components of learning English is Grammar, and the intrinsic part of it is Parts of Speech (PoS), where the majority of Malaysian students in higher institutions are still grappling to understand its use in sentences. This study aims to compare conventional method to e-learning method on its effectiveness in the teaching and learning of PoS. The application of Stanford PoS tagging has been used to analyze the PoS in every single word of the sentences extracted from the articles in The New Straits Times Online (NST Online). This quantitative research study adopted a comparative analysis in analyzing its findings. The results were statistically analyzed using The Statistical Package for the Social Science (SPSS) for statistical analysis. These findings of the research reveal a significance difference between the score from students using E-paper and the score from students not using E-paper in learning Grammar. Independent t-test was carried out to compare mean between the two groups. The result shows a significance difference ( $\mathrm{p}$-value $=0.007, \mathrm{t}=-2.774$ ) between the two groups of students' score. The mean performance of the students using E-paper shows a higher percentage compared to those not using E-paper. As students nowadays spend most of their time with electronic gadgets, this is an innovative way to capture their interest to spend more time on quality reading materials via electronic newspaper, simultaneously learning Grammar by going to the crux of its core by identifying the PoS of each word in sentences using new pedagogical strategy of PoS tagging.
\end{abstract}

Keywords: PoS Tagging, E-newspaper, grammar teaching pedagogy, E-learning, Parts-of-Speech

\section{Introduction}

It is a well-known fact, that teaching English Grammar is an arduous task causing lack of motivation and concentration to learners in developing the learning of grammar-based inputs of English Language in the classroom (Chowdhury, 2014). Due to that reason, it has caused students to lose interests and they considered learning Grammar as boring and dry, eventhough they are aware of the importance of mastering it. Thus, educators need to find ways and strategies to make teaching Grammar, specifically Part of speech (PoS) to be more interesting and comprehensible to attract the attention of the English language learners.

In the same vein, students of higher learning institutions in Malaysia, despite many years of learning English language are still grappling with their English Language basic concept of Grammar, in general, and on many times forming incorrect sentence constructions in their academic writing (Rashid, Rahman, \& Yunus, 2017). That is concurred by Darmi \& Albion (2013), who said that debates continue about the reasons as to why local graduates are not competent in the L2, i.e. English language.

With the help of computer and internet, E-learning brings the changes of pedagogical strategies and ultimately improves the efficiency of teaching and learning. If we do not change, the new generation will not be satisfied with school education, even for the next 30 years (Huiwei, 2012). Thus, this is a small contribution to the process of teaching and learning Grammar in the era of technology. As students nowadays are very attached to their gadgets, this study will in one way or another help to contribute ideas for the English language lecturers and teachers to teach Grammar in a fun way. As stated by Shyamlee \& Phil (2012), the tradition of English teaching has been drastically changed with the remarkable entry of technology. 
The integration of e-learning with English language learning will make a big impact on students learning process. Hence, this study has advocated learning English grammar via reading an online newspaper (e-paper). Mehta (2010) concurred that reading newspapers on regular basis is considered as a good practice and it would produce a great impact to learners in schools and higher institutions. It is observed that the students who read newspapers regularly are more proficient and aware of the updates of local and international scenarios. By reading newspapers, the students would become more knowledgeable on issues pertaining to various subjects including social-political-business issues, sports, entertainment, education and various others. Furthermore, the practice of using English newspapers not only helps the students in the ESL classroom but also in the mundane affairs of their life. They will be encouraged to improve their vocabulary, grammar and thinking skills as regular newspaper reading can provide them with opportunity to express and exchange their ideas on a wide variety of issues.

Part-of-speech tagging aims to assign a specific tag to each word of a sentence to indicate the function of that word in a specific context based on certain guidelines (Btoush, Alarabeyyat, \& Isa, 2016). The various applications of PoS tagging would be very helpful in assisting the language learners in identifying grammar correction and recognizing the many categorization of part-of-speech in sentences, namely nouns, verbs, pronouns, prepositions, adverbs and many other tags. The process of assigning description to the given word is called Tagging. The descriptor is called tag. The tag may indicate one of the parts-of-speech like noun, pronoun, verb, adjective, adverb, preposition, conjunction, and interjection. The ambiguity which is identified in the tagging module is resolved using the grammar rules. The main challenge in POS tagging is to resolving the ambiguity in possible POS tags for a word. Despite the challenge, the great benefits in making the students to recognize and comprehend the usage of the words in sentences in English language articles, overrule it.

This study aims to compare conventional methods to e-learning methods on its effectiveness in the teaching and learning of PoS. Another purpose of this study is to help the English Language lecturers or teachers to find out the most effective way of teaching PoS in class. In the research study, the use of PoS tagging on E-newspaper has been proven to improve students' performance in Grammar on the course that they were taking, English for Academic Purpose. New Straits Times Online had been chosen as the source for the news article to be analyzed using the PoS tagging approach of learning, as it is known as an established newspaper in Malaysia, having been found in 1845 as 'The Straits Times', and was reestablished in 1974, as 'New Straits Times'. It has been used by many educators previously as a teaching tool in the classroom not only for primary and secondary schools but also in higher institutions. Hence, this approach of teaching is highly recommended to be applied in teaching Grammar, specifically $\mathrm{PoS}$ as it has dual purposes of language skills, namely reading and grammar. This approach of teaching would also help learners to instill the awareness of reading quality reading materials rather than learning Grammar by going to the crux of its core through analyzing the PoS for each word in the sentences.

\section{Review of Related Literature}

The use of a printed newspaper as a teaching tool in classrooms has been practiced for quite some time in schools and higher institutions in Malaysia. Due to its immense benefits to the improvements of student's proficiency in English language, it is still popular up to now. Reading newspapers can help students acquire higher level of proficiency in English (Ahmmed, 2016) where teachers are using it for various kind of activities. E-newspaper, somehow, is yet to be tapped its relevance as a teaching tool.

Now that the e-reading devices have grown in number, readers are facing a new presentation of electronic text changing the venues of their reading experiences (Brown, 2001). Today's reading experience differs substantially compared to the times when there was only printed text. An increasing amount of electronic text-e-mails, web pages, text-messages, online catalogues and databases, e-newspapers and e-books are being used by the readers of twenty-first century. Hence, it is high time, and just wise for the educators in this century to make use of the new technology, e-newspaper in this context, for their Grammar teaching pedagogy to attract students' interests.

Based on the research by Darmi \& Albion (2013), almost 80 percent of students are inclined to read a printed digital text in order to understand the text with clarity. Also, nearly $68 \%$ of the respondents are being reported to understand and retain more information when they read printed media. On the contrary, merely 4 percent reported otherwise.

As for grammar teaching, conventional method is still widely being practiced in the classrooms (Wotley, 2017). Nevertheless, using PoS tagging for language teaching pedagogy is new. In a previous research of PoS tagging, Chowdhury et al. (2004) implemented a rule based PoS tagger. Their study mainly dealt with analysing the part of morphology rather than analysing using the PoS tagger to analyse sentences from articles taken from an E-newspaper. A morphological analyzer indeed provides some PoS tag information, but using a PoS-tagger on 
E-newspaper, somehow, is yet to be tapped to be employed as a teaching tool. It is a new trend.

\section{Methodology}

\subsection{The Study Population}

The study was conducted on 95 first semester students of University Technology MARA (UiTM) who had taken a course of English for Academic Purpose, which is a requirement for first semester students in the university. The samplings comprised of 44 Chemical Engineering students and 51 students of Mechanical Engineering.

\subsection{Data Collection}

The subjects were assigned as experimental and control groups. Both groups took English for Academic Purpose course, four hours a week, and the application took two hours a week for the duration of seven weeks. Data were gathered based on their Final Semester Test, where the focus was on the Grammar section, which carries 10\% out of $40 \%$ of the overall results. The results were statistically analyzed using The Statistical Package for the Social Science (SPSS).

In carrying out this activity, the participants were required to get an article from an e-newspaper, namely New Straits Times online. Students usually choose the materials in subjects which they are interested in. Interest in the material itself is "direct interest" to produce better learning (Huawei, 2012). Following that, words of designated PoS were highlighted from the article. The identified words were then categorized based on their respective category, namely Nouns, Verbs, Adverbs, Adjectives, Conjunctions or Pronouns, into its respective columns. Self-checking was then done using the application of Stanford PoS tagging on the accuracy of the categorization of words.

How the process was conducted is summarized below.

Step 1 - Selection of articles from News Straits Times online (NST Online).

Step 2 - Parts of Speech identification, by highlighting the designated words from the chosen article.

Step 4 - The selected words would be categorized into their respective category of Part-of-Speech, namely Nouns, Verbs, Adjectives or Articles, to name a few, into its respective columns.

Step 5 - The assessments was done via participants' self-checking using an application of Stanford PoS Tagging Step 6 - This activity would be carried out on weekly basis until the desired results of the students is achieved.

\section{Data Analysis and Findings}

\subsection{Demographic Profile}

Figure 1 shows the percentage comparison of respondents from Chemical Engineering (EH110) and Mechanical Engineering (EM110) students. The percentage comprised of 45\% Chemical Engineering students while another 53\% were first semester Mechanical Engineering students. They were selected from the same faculty of Engineering. The different courses being chosen was for the purpose of showing the positive effects from usage of e-newspaper on the group of students with lower proficiency in English Language, i.e., Diploma in Mechanical Engineering where the requirement for entering the university, for this group of students, is just a "pass" in Malaysian Higher Education Examination (SPM), compared to the students of Chemical Engineering where the requirement to enter into the course is a credit in English Language for the same examination.

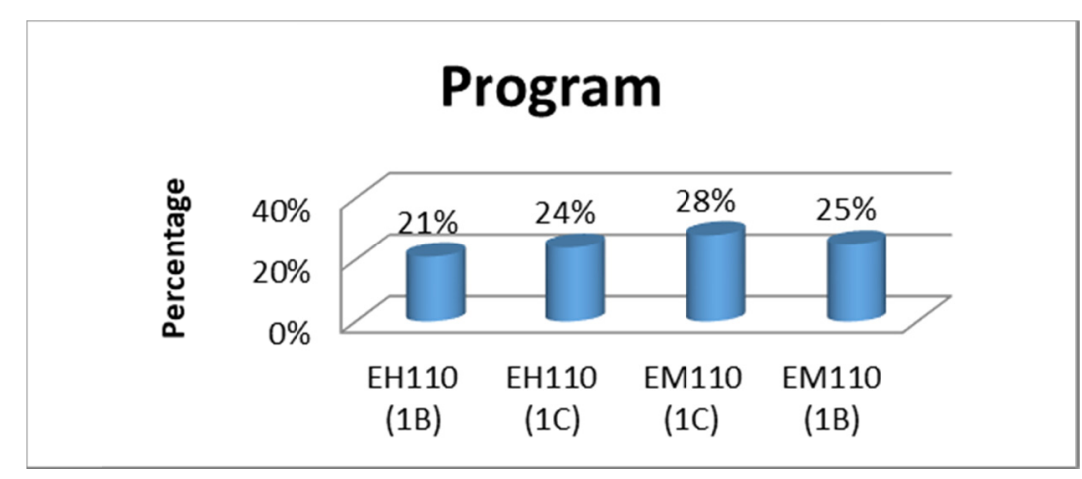

Figure 1. Comparison in percentage between groups 


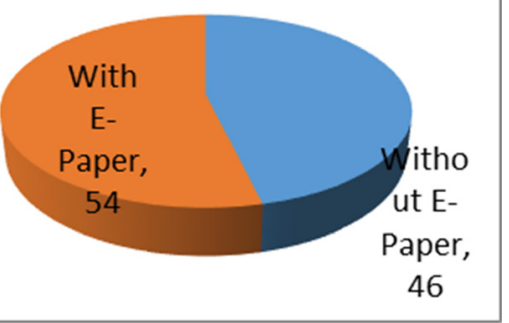

Figure 2. Comparison in percentage between e-paper and without e-paper

\subsection{Cross Tabulation Table Between Four Groups}

Table 1. Comparison between e-newspaper and without e-newspaper between groups

\begin{tabular}{lllll}
\hline Percentage & EH1B & EH1C & EM1A & EM1B \\
Grade & Without E-Newspaper & & 33.33 & 25.00 \\
\hline A $(8-10)$ & 14.29 & 8.70 & 48.15 & 66.67 \\
B $(5-7)$ & 61.90 & 69.57 & 18.52 & 8.33 \\
C $(1-4)$ & 23.81 & 21.74 & \\
\hline
\end{tabular}

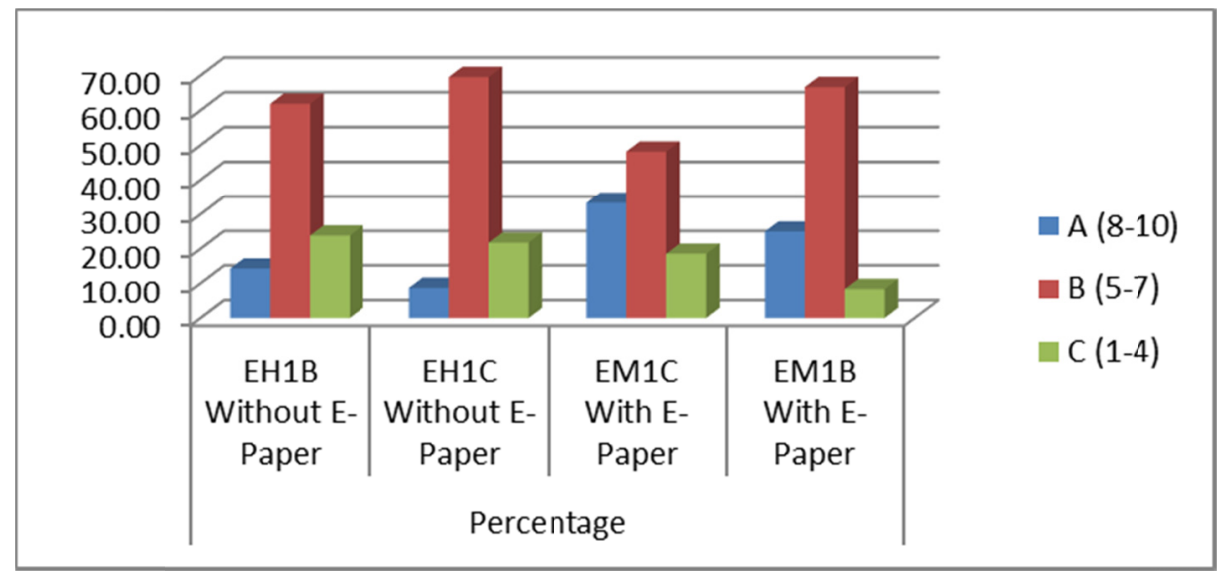

Figure 3. Comparison between e-newspaper and without e-newspaper between groups

\subsection{Independent T-Test}

This study was interested to know whether there is a significance difference between the score of learning with E-newspaper and score without E-newspaper. Independent t-test was carried out to compare mean between the two groups. The result presented in Table 3 shows that there is a significance difference $(\mathrm{p}$-value $=0.007, \mathrm{t}=$ -2.774) between the two groups of student score. This means that mean performance of student using E-newspaper is better than without using E-newspaper.

Table 2. Descriptive statistics

\begin{tabular}{llll}
\hline Status & Sample size & Mean & Standard Deviation \\
\hline Without E-newspaper & 44 & 5.50 & 1.372 \\
With E-newspaper & 51 & 6.39 & 1.710 \\
\hline
\end{tabular}


Table 3. Independent samples test

\begin{tabular}{llllll}
\hline t-value & $\begin{array}{l}\text { Degree } \\
\text { freedom }\end{array}$ & of & $\begin{array}{l}\text { Significance } \\
\text { values }\end{array}$ & Mean Difference & $\begin{array}{l}\text { Standard Error } \\
\text { Difference }\end{array}$ \\
-2.774 & 93 & 0.007 & -0.892 & 0.332 & \\
\hline
\end{tabular}

Based on the results obtained from the data analysis, there is a significant difference of performance in terms of percentage for each band. The group of Diploma in Chemical Engineering, EH1B and EH1C are the target groups which use conventional method in learning PoS, whereas, the groups of Diploma in Mechanical Engineering, EM1A and EM1B are two groups learning PoS using E-newspaper. Table 1 reveals that the percentage of marks for Band A (8-10 marks) for groups with E-newspaper outperformed the groups without E-newspaper where students using E-newspaper recorded $10 \%$ and $20 \%$ respectively compared to the group without E-newspaper. Also, the percentage of students who earn Band C (1-4 marks) who use E-newspaper is lower than the group without E-newspaper.

The comparison using Independent Samples t-Test also proves that there is a significant difference between the two groups, score with e-newspaper and score without e-newspaper. This shows that the groups using the E-newspaper performed better than the groups without E-newspaper in terms of Band A and Band C. Thus, the use of E-Paper has definitely improved the students' knowledge in PoS.

\section{Conclusions and Recommendations}

Innovative teaching- Gadget embedded pedagogy is highly recommended to be applied by language educators to instill the technology awareness in their teaching where it can attract students' motivation to learn English, specifically to understand PoS. One way to encourage improvement in teaching and learning efficiency is through the use of PoS tagging on e-newspaper.

The effect of technology has become huge in teaching and learning the language where it can lead to advanced learning results (Sharma, 2009). This is proven in this study, whereby, the use of PoS tagging on e-paper has significantly improved the performance of language learners compared to the application of conventional teaching method. Moreover, it will instill awareness on importance of reading a newspaper among students of higher institutions.

As the fourth industrial revolution slowly emerging in our life, menacingly, for the conventional method practitioners, language educators are threatened to hone their skill on language teaching pedagogy that could entice new generation of students who are greatly attached to their gadgets to learn grammar.

Further research is recommended to be carried out using a PoS tagging, not restrictive to improving Grammar learning, but also to improve other skills in English proficiency amongst the students of English as a second language (ESL), as well as students of English as a foreign language (EFL) in their countries respectively.

\section{References}

Ahmmed, R. (2016). Effectiveness of reading English newspapers for improving vocabulary and reading skills of students of Dhaka University. The Millennium University Journal, 1(1), 68-76.

Brown, G. J. (2001). Beyond print: Reading digitally. Library Hi Tech, 19(4), 390-399. https://doi.org/10.1108/07378830110412456

Btoush, M. H., Alarabeyyat, A., \& Isa, O. (2016). Rule based approach for Arabic part of speech tagging and name entity recognition. International Journal of Advanced Computer Science and Applications, 7(6), 331-335.

Chowdhury, M. H. (2014). Teaching grammar in the English language classrooms in Saudi Universities. Express, an International Journal of Multi-Disciplinary Research, 1(1), 1-9.

Chowdhury, A., Uddin, M., Imran, M., Hassan, M. M., Mohammad, N., Shahnur, M., \& Haque, M. E. (2004). Parts of speech tagging of Bangla Sentence. Retrieved from http://www.academia.edu/2021643/Parts_of_Speech_Tagging_of_Bangla_Sentence

Darmi, R., \& Albion, P. (2013). English language in Malaysian education system: Its existence and implication. Retrieved

from http://www.academia.edu/4275280/English_language_in_the_Malaysian_education_system_Its_existence_ and_implications

Huiwei \& CSR Asia. (2012). The role of ICT in realising education for all by 2030 — CSR Asia. Retrieved from 
http://www.csr-asia.com/download/ICT4SDG4-Final-Version.pdf

Mehta, N. K. (2010). English newspapers: Exploring innovative methodological paradigm-A study into classroom dynamics. Romanian Journal of Education, 1(1), 55-60.

Rashid, R. A., Rahman, S. B. A., \& Yunus, K. (2017). Reforms in the policy of English language teaching in Malaysia. Policy Futures in Education, 15(1), 100-112. https://doi.org/10.1177/1478210316679069

Sharma, P. (2009). Controversies in using technology in language teaching. Retrieved from https://www.teachingenglish.org.uk/article/controversies-using-technology-language-teaching

Shyamlee, S. D., \& Phil, M. (2012). Use of technology in English language teaching and learning: An analysis. In International Conference on Language, Medias and Culture IPEDR vol. 33, Singapore (pp. 150-156). Singapore: IACSIT Press.

Wotley, D. (2017). A personal narrative of an English teacher in Japan on language, tacit knowledge and $\begin{array}{lllll}\text { language education. Journal of Nusantara Studies, } & \text { 2(2), 127-138. }\end{array}$ https://doi.org/10.24200/jonus.vol2iss2pp127-138

\section{Copyrights}

Copyright for this article is retained by the author, with first publication rights granted to the journal.

This is an open-access article distributed under the terms and conditions of the Creative Commons Attribution license (http://creativecommons.org/licenses/by/4.0/). 